\title{
Cortázar: entre la cultura pulp y la denuncia política
}

\author{
Córtazar in the middle of Pulp culture and political denunciation
}

\author{
Jaume Peris Blanes \\ Universitat de València, Facultad de Filología, Departamento Filología Española, València, España. \\ Correo electrónico: jaume.peris@uv.es
}

En Fantomas contra los vampiros multinacionales (1975) Julio Cortázar articula una lúdica narración verbal con las páginas de un cómic y las actas de la segunda sesión del Tribunal Russell, configurando un insólito híbrido entre novela gráfica, relato verbal e informe de denuncia. El texto constituye un espacio de negociación entre diferentes formas de entender la relación entre literatura, cultura y política, que trata de responder a las tensiones y debates que, en torno a esa problemática, habían tenido lugar en América Latina en la década anterior. Específicamente, el texto de Cortázar responde literariamente al auge de lo que se denominó 'antiintelectualismo', apropiándose de algunos de sus elementos y dándoles una figuración literaria.

Palabras clave: Cortázar, Fantomas, Tribunal Russell, política, antiintelectualismo.

In Fantomas against the multinational vampires (1975) Julio Cortázar mixes a verbal narration with comic strips and with the Russell Tribunal political report. The text is a place of negotiation between some different ways of understanding the relationship between literature, culture and politics. Cortazar was trying to give an answer to the latinoamerican intellectual debates on these issues.

Key words: Cortázar, Fantomas, Russell Tribunal, politics, anti-intelectualism.

\section{INTRODUCCIÓN}

En 1975, Julio Cortázar publicó Fantomas contra los vampiros multinacionales. Una utopía realizable en la editorial mexicana Excelsior. Se trataba de un extenso relato, de 77 páginas en su versión original, que mezclaba la narración verbal con las páginas de un cómic y con las actas reales de la segunda sesión del Tribunal Russell, configurando un insólito híbrido entre novela gráfica, relato verbal e informe de denuncia. El título anunciaba irónicamente el cruce de géneros sobre el que se iba a sostener la narración: un personaje de la cultura masiva, identificado con la narración policíaca y pulp, iba a servir de estrategia narrativa para representar paródicamente el poder y la influencia de las sociedades multinacionales en América Latina.

Pero Fantomas... no sólo era un relato insólito por su articulación de diferentes códigos ni por su utilización de referentes de la cultura masiva, sino porque su textura 
difería notablemente de las anteriores narraciones breves de su autor. El año anterior Cortázar había publicado Octaedro (1974), que supuso una vuelta del autor a la poética del cuento que ya había ensayado en Final del juego (1956) y Todos los fuegos el fuego (1966), tras un paréntesis en que, además de sus grandes novelas, había experimentado con formas literarias híbridas y liminares como Último Round (1967) o La vuelta al día en ochenta mundos (1969). Si los cuentos de Octaedro parecían señalar una vuelta a la poética concisa y enigmática del realismo fantástico cortazariano, Fantomas... presentaba un tono mucho más ligero e irónico, lleno de juegos metaliterarios, pero despojado de la gravedad ontológica de sus cuentos clásicos.

Frente a esas narraciones, Fantomas... presentaba otra diferencia fundamental: mientras que la poética del realismo fantástico exigía espacios privados ajenos a la Historia en los que lo cotidiano entraba en conflicto con la emergencia de órdenes velados y ocultos o conexiones fantásticas entre diferentes realidades, el relato de Fantomas... insertaba su trama en un contexto histórico y político muy definido, marcado fundamentalmente por la declaración del Tribunal Rusell, en la que condenaba la intervención de la administración estadounidense en los golpes de estado latinoamericanos de los setenta y el clima de terror represivo que se había desatado en el continente.

Si bien las narraciones breves escritas hasta el momento no habían incorporado elementos que aludieran directamente a la realidad política e histórica de América Latina, ${ }^{1}$ su extensa novela Libro de Manuel (1973) había supuesto un giro radical en la producción de Cortázar, ya que en ella trataba de inscribir los conflictos políticos mayores de la realidad latinoamericana en la matriz de experimentación narrativa que había ensayado en sus novelas anteriores, Rayuela (1963) y 62. Modelo para armar (1969). En ese sentido, Fantomas... era un texto que continuaba la indagación de Libro de Manuel más que la de Octaedro, ya que, aunque en una tonalidad y un registro muy diferentes, la cuestión que subyacía a ambos textos era prácticamente la misma: ¿cómo representar y dar cuenta del conflicto político contemporáneo y de la violencia (económica, simbólica y represiva) que estaba sufriendo América Latina desde los códigos propios de la literatura? ¿Cómo inscribir, pues, la política práctica en la poética de la narración que Cortázar llevaba casi dos décadas afinando?

En este artículo se tratará de analizar Fantomas contra los vampiros multinacionales desde esa óptica, detallando las estrategias narrativas en que se sostenía y reflexionando sobre los registros heterogéneos de la representación que el texto ponía en marcha. La acusada variedad de estrategias casi contradictorias, sus múltiples y no siempre bien articuladas tonalidades y texturas narrativas, nos hacen pensar en Fantomas... como un espacio de negociación entre diferentes poéticas. En ese sentido, continuaba las indagaciones de Libro de Manuel, que había explorado la posibilidad de hacer convivir una poética neovanguardista con las nuevas modalidades de la enunciación testimonial (ver Peris Blanes 2006), pero lo hacía de un modo muy diferente, que implicaba una concepción diversa de la relación entre escritor y lector y que daba una salida nueva al viejo problema de la relación entre forma literaria e intervención política, que había sobrevolado la escritura de Cortázar desde principios de los años sesenta.

Salvo en el conocido caso de "Reunión”, donde representaban los primeros días de la lucha del Che Guevara en Sierra Maestra. 


\section{LO POLÍTICO Y LA AUTONOMÍA LITERARIA}

La cuestión de lo político en la obra de Cortázar se hallaba ligado a un problema más amplio: el de la conflictiva relación del discurso literario con la realidad social e histórica y con los proyectos de emancipación social que habían aparecido en América Latina en las últimas décadas. Fue ésta una cuestión que atravesó el debate literario latinoamericano durante todos los años sesenta y principios de los setenta y que obtuvo respuestas diferentes y contradictorias por parte de escritores e instituciones culturales, generando enconadas polémicas literarias que llegaron a alcanzar un grado espectacular de virulencia.

La Revolución Cubana había producido una transformación global en la cultura latinoamericana, erigiéndose en referente fundamental de los intelectuales de izquierda y amplificando las expectativas de cambio social y cultural que éstos habían encarnado durante las décadas anteriores (Franco 2003: 119-158), llegando a convertirse, incluso, en la fantasía de numerosos intelectuales occidentales que vieron en la Cuba castrista una materialización de las utopías colectivistas de los sesenta (De la Nuez 2006). Pero, la Cuba de los sesenta fue, además, el epicentro de un intenso debate sobre el rol de la cultura latinoamericana y los intelectuales de izquierdas en tiempos de revolución, que modificó sustancialmente las representaciones y el valor de éstos en todo el continente.

El concepto sartreano de compromiso vehiculó en los primeros sesenta buena parte de las representaciones del intelectual que habían construido los escritores ligados a la revolución. Pero, en la segunda parte de la década, con el endurecimiento de la política cultural cubana y la emergente militarización social del país, las exigencias de participación revolucionaria devaluaron la noción-paraguas de compromiso y desacreditaron las competencias específicas del intelectual para intervenir en la sociedad revolucionaria (Pérez-Stable 1993: 203-210). Así, el paso del paradigma del intelectual comprometido al del intelectual revolucionario, estuvo marcado por lo que Claudia Gilman ha definido como el auge del 'antiintelectualismo' (2003: 143232), es decir, la pérdida de confianza en las competencias específicas del escritor para intervenir socialmente, que acabaría por situar a los intelectuales bajo sospecha y convertiría al campo intelectual en un espacio de autovigilancia continua. ${ }^{2}$

En ese contexto, la concepción liberal del escritor, que le otorga una función eminentemente crítica frente a la sociedad -sea ésta cual sea- fue considerada como un resto de una concepción burguesa y elitista de la cultura, a la que fueron asociados figuras mayores de la literatura latinoamericana como Carlos Fuentes, Vargas Llosa y, en ocasiones, el propio Cortázar, quien tuvo que responder recurrentemente a los reproches de no pocos de sus colegas. La tensión entre las instituciones cubanas y los intelectuales ‘amigos de la revolución’ no hizo sino crecer con el paso de los años hasta llegar a un punto crítico a principios de la década de los setenta, cuando la retórica y el imaginario antiintelectual fue gramaticalizándose hasta aparecer como un discurso más o menos codificado y reconocible.

Fidel Castro, en sus Palabras a los intelectuales de 1961, les había ya advertido que su trabajo debía inscribirse en los límites de la práctica revolucionaria y Ernesto Guevara, en su artículo sobre el Hombre Nuevo (1965), señalaba a los intelectuales como portadores de los valores pre-revolucionarios que la revolución debía trascender. 
El 'caso Padilla’3 fue, sin duda, la culminación de esa dinámica antiintelectualista en que habían entrado las autoridades cubanas y no pocos de los escritores ligados a la izquierda política latinoamericana. Pero lo que latía bajo ese violento conflicto era una concepción diferente de la relación que debían mantener los intelectuales con la arena política. Para unos, los intelectuales debían someter los objetivos literarios a los objetivos inmediatos de la revolución y desarrollar poéticas en clave realista, acentuando el poder comunicativo de la obra sobre la conciencia de los lectores; para otros, el trabajo intelectual era necesariamente un elemento crítico dentro de la sociedad -fuera ésta la que fuera- y, además, los logros estéticos eran tan importantes como los logros políticos. Tal como señala Gilman, estos segundos “planteaban como su tarea la de hacer 'avanzar' el arte del mismo modo que la vanguardia política hacía 'avanzar' las condiciones de la revolución, y también formulaban que el compromiso artístico-político implicaba la apropiación de todos los instrumentos y conquistas del arte contemporáneo” (2003: 144).

Cortázar fue uno de los más firmes defensores de esta segunda opción y en diferentes textos señaló la relación de complementariedad entre la escritura literaria y la acción política: la paridad jerárquica entre una y otra abría la posibilidad de realizar, en el ámbito de la literatura, una revolución más profunda de la que los dirigentes revolucionarios habían realizado en el ámbito de la política práctica. ${ }^{4}$

Pocos dudarán de mi convicción de que Fidel Castro o Che Guevara han dado las pautas de nuestro auténtico destino latinoamericano; pero de ninguna manera estoy dispuesto a admitir que los Poemas humanos o Cien años de soledad sean respuestas inferiores, en el plano cultural, a esas respuestas políticas (Cortázar [1969] 2006: 402-403).

En su conocida polémica con Óscar Collazos, expuso la idea de que más que someter la literatura a los dictados de la revolución, la tarea del escritor debía consistir en "revolucionar la literatura" (ídem.). En ese sentido, la experimentación llevada a cabo en Rayuela o 62. Modelo para armar, donde ponía en práctica una poética neo-vanguardista que deconstruía y dislocaba las estructuras tradicionales de la narración, podían ser consideradas intervenciones políticas de primer orden, ya que modificaban el modo usual de percibir la realidad y de representarla y, por ello, contribuían a una profunda transformación en la posición del sujeto con respecto al mundo. Desde la posición de Cortázar, la literatura que apoyaba de forma plana el proceso revolucionario utilizando formas de narrar tradicionales conseguía un objetivo contrario: consolidar una forma de comprender y de experimentar el mundo caduca, tradicional y, por tanto, firmemente antirrevolucionaria.

El caso es bien conocido y está bien estudiado en Gilman (2003: 233-265). Pueden hallarse los documentos centrales de la polémica en Casal (1971) y una narración pormenorizada del caso en Alburquerque Fuschini (2001).

4 Cortázar siempre mostró admiración por los guerrilleros que habían conseguido tomar el poder por medio de las armas, pero al mismo tiempo criticó el proceso de institucionalización de la revolución que, según él, había convertido a muchos de los revolucionarios en puritanos burócratas: “ ellos [los compañeros militantes] opinan que el humor no tiene nada que ver con la revolución. Yo creo que sí tiene que ver. En América Latina, libro dos grandes batallas, una por la liberación humorística, otra por la liberación erótica, por un humorismo y erotismo integrales que nos liberen de todos los tabúes que nos llegan, sobre todo, de la tradición hispánica [ ] Contra los comisarios que no tienen sentido del humor y además son malos amantes” (Citado por Gundermann 2004: 1) 
Si bien hasta finales de los sesenta Cortázar había insistido en esa poética neovanguardista y la había llevado hasta el límite en 62. Modelo para armar, la entrada de la década de los setenta estuvo marcada por la búsqueda de nuevas fórmulas narrativas que no fiaran a la experimentación de los códigos narrativos todo su potencial político. Sin duda que la agria polémica en torno al 'caso Padilla' influyó en ese cambio de modelo, ${ }^{5}$ pero también lo hizo la evolución del panorama político y social en América Latina y el creciente clima de violencia y represión que se iba generalizando en el Sur del continente.

Libro de Manuel fue, sin duda, la respuesta de Cortázar a las exigencias de la nueva situación: no valía ya con mostrar públicamente su rechazo moral ante las injusticias de América Latina y apoyar los proyectos progresistas, sino que había que hallar una fórmula que integrara la estética experimental e indagadora de sus novelas con el universo violentado y represivo que iba adueñándose del Cono Sur latinoamericano. Libro de Manuel supuso, en ese sentido, el resultado de la negociación entre la poética neovanguardista de sus anteriores novelas y las poéticas documentales y testimoniales que estaban transformando el campo literario latinoamericano en esos años. Su parte final, en la que moría el narrador de la historia y su lugar lo ocupaban los testimonios -extraídos de la prensa- de numerosos supervivientes de la represión argentina, metaforizaba sutilmente esa tensión entre diferentes poéticas y la dificultad de integrarlas en una estética coherente (Peris Blanes 2006).

\section{ENTRE LA ESTÉTICA PULP Y LA DENUNCIA POLÍTICA}

Fantomas..., aunque de un modo mucho menos ambicioso, continuó con la indagación político-literaria de Libro de Manuel, y constituyó una nueva tentativa de dar cabida a la realidad de la violencia y la represión en una narración que, a la vez, jugara con los elementos internos de la narración y deconstruyera los materiales del relato. Con una sugestiva variación: si Libro de Manuel había tomado sus referentes discursivos y sus estrategias constructivas de la escena de vanguardia (Stockhausen, Rothko y otros exploradores de la obra abierta, en el sentido que le da Eco [1965]), Fantomas... se servía de elementos claramente identificados con la cultura masiva, como el cómic y la estética pulp. De hecho, Cortázar proponía un juego narrativo en el que aparecían fragmentos de la historieta mexicana, publicada unos meses antes, "La inteligencia en llamas”, ${ }^{6}$ en la que el autor argentino aparecía como personaje secundario -junto a otros escritores como Susan Sontag, Octavio Paz o Alberto Moravia- de una aventura de Fantomas. ${ }^{7}$

Su respuesta al caso Padilla, el poema-ensayo "Policrítica a la hora de los chacales", condensaba buena parte de las contradicciones estéticas y políticas de Cortázar en torno al problema de la relación entre literatura y poder. Hemos analizado ese texto en detalle en Peris Blanes (2009).

6 Con guión de Guillermo Matré y dibujos de Victor Cruz, publicado por la editorial Novaro en febrero de 1975, como volumen 201 de su serie de Fantomas: la amenaza elegante.

M.A. Barataud ha hecho un adecuado seguimiento de la figura de Fantomas en el cómic mexicano: "En un principio, los tebeos de la Editorial Novaro coincidían con las historias publicadas por Souvestre y Allain: eran adaptaciones más o menos fieles de las historias francesas en tebeos traducidos. Se mantenía entonces el lado criminal del robo de obras de arte así como la presencia del policía que lo perseguía [ ]. A lo largo del tiempo y con la fama creciente de la serie popular (tanto en Francia como en México), el protagonista de Fantomas mexicano se modificó, alejándose 
Jean Franco ha señalado que esta diferencia marcó una inflexión en la obra cortazariana, en la medida en que la cultura masiva supuso un referente que le permitió crear una complicidad diferente con el lector potencial. Para Franco, la elección del cómic popular como elemento de diálogo formal estaba ligada, pues, a una voluntad de democratización literaria que iba más allá de la tradicional desconfianza de la vanguardia con respecto al público de la cultura masiva (1979: 11) y que, por tanto, abría las puertas a una nueva forma de relación con el lector. Lo cierto es que desde la segunda mitad de la década de los sesenta la novela latinoamericana había tematizado insistentemente algunos referentes de la cultura masiva, ${ }^{8}$ deshaciendo la tradicional brecha entre la alta y la baja cultura que había estructurado las letras latinoamericanas hasta entonces.

El texto de Cortázar participaba, sin duda, de ambos movimientos, y exhibía su ruptura de las tradicionales distinciones culturales como un acto de libertad creativa que, además, le abría las puertas a un diálogo con los consumidores de la cultura masiva. Esa voluntad de extender su literatura a otros lectores poco identificados con la estética vanguardista podría considerarse contradictoria con algunas de sus afirmaciones de años anteriores, pero hallaba su justificación en uno de los propósitos centrales que Cortázar dio a Fantomas..., y que apenas se preocupaba de ocultar: dar visibilidad y publicidad a las conclusiones elaboradas por el Tribunal Rusell sobre la naturaleza de la represión en América Latina, en cuyas sesiones Cortázar había participado como miembro activo, a las que durante todo el texto aludiría y que, además, se hallaban reproducidas como anexo en la primera edición de Fantomas...

Es probable, de hecho, que la tonalidad ligera del texto, su apuesta directa por el divertimento y el placer narrativo, así como su utilización irónica del cómic y la estética pulp, tuvieran como objetivo captar la atención del lector medio sobre lo que realmente le interesaba en ese momento: la declaración del Tribunal Russell, la situación de represión generalizada que se estaba viviendo en Chile y la escalada de la violencia política que estaba ganando Argentina. Esa naturaleza hasta cierto punto secundaria de la narración -con un objetivo pragmático muy claro, más allá del propiamente literario- hace de Fantomas... un texto extraño en la producción cortazariana, pero no por ello menos interesante para analizar las tensiones que se dan en su interior, que son las propias del campo literario latinoamericano de mediados de los setenta, confrontado a las urgencias de una realidad social acuciante.

Así pues, el uso del cómic de Matré y Cruz, más allá de la anécdota personal, ${ }^{9}$ puede pensarse como un modo de acercarse a un público y a un registro cultural más amplio, que diera más resonancia potencial a las actas del Tribunal Russell. Pero también debe pensarse como una nueva indagación en las posibilidades de la

del protagonista francés [ ]. La adaptación se hace reescritura: sigue siendo un ladrón [ ] pero muta a un filántropo millonario que tiende a tener rasgos de Robin Hood. En episodios más tardíos, se opone a la corrupción de los Grandes del mundo a favor de los desafortunados, excepto las obras de Arte inestimables que se las guarda para sí mismo como tesoro. El Fantomas mexicano aparece entonces como una amalgama de Fantômas, de Arsène Lupin y de los superhéroes americanos como Batman” (Barataud 2009: 3).

8 Por ejemplo, las obras de Manuel Puig La traición de Rita Hayworth (1968) o Boquitas pintadas (1969) habían inscrito en estructuras narrativas muy complejas algunos referentes del cine norteamericano, y habían dado un rol fundamental en la construcción de la subjetividad a fantasías personales relacionadas con ellos.

9 Cortázar explicó que, sorprendido por el hecho de que los editores lo hubieran convertido en personaje del cómic sin consultarle, decidió apropiarse de la historieta para incluirla en su relato y modificar su sentido (Barataud 2009: 11). 
narración literaria en diálogo con otros soportes discursivos. Si en Libro de Manuel las noticias de prensa reales aparecían reproducidas en la novela y determinaban las conversaciones, reflexiones y acciones de los personajes, en Fantomas... eran las viñetas del cómic, leídas por el narrador (trasunto del propio Cortázar) las que hacían avanzar la acción y disparaban su alocada trama.

Ese diálogo irónico con las viñetas del cómic tenía una significación peculiar, ya que permitía a Cortázar estructurar el texto a partir de un conflicto entre los diferentes soportes y niveles narrativos. Esa idea de conflicto interno no carece de importancia a la hora de evaluar el texto, pues si su objetivo más directo parecía ser la denuncia pública, directa y explícita de una situación de represión, Cortázar vehiculó todo ello a través de una narración que, a pesar de su tonalidad lúdica, presentaba en su interior una serie de violencias enunciativas y rupturas de las convenciones discursivas que daban una dimensión más compleja al texto. La idea vanguardista de collage o de montaje en sentido einseinsteniano no era ajena a dicha concepción del relato como conflicto entre materiales diversos. ${ }^{10}$ Acerquémonos a la construcción interna del relato para verlo mejor.

\section{LAS HERIDAS DE LA NARRACIÓN}

De entrada, el relato se abría con una fórmula que inscribía al lector en el universo de la literatura ficcional, parodiando el modo en que una cierta tradición literaria (la del Quijote, por ejemplo) introduce al principio de cada capítulo los componentes fundamentales de su trama antes de narrarlos: "De cómo el narrador de nuestra fascinante historia salió de su hotel en Bruselas, de las cosas que vio por la calle y de lo que le pasó en la estación de ferrocarril” (2). ${ }^{11}$

Pero, además de marcar firmemente el estatuto literario de la narración, el titulillo aludía a la figura del 'narrador de nuestra fascinante historia'. Se trataba, claro, de una referencia irónica y paradójica, ya que la voz que hablaba era, sin duda, la del narrador y, por tanto, carecía de sentido nombrarlo en tercera persona. Ese procedimiento atravesaba todo el texto y, aparte de su carácter irónico, cumplía dos objetivos simultáneos. Por una parte, al modo de ciertos textos de vanguardia, mostraba la presencia del sujeto de la enunciación, subrayando el carácter artificial de la narración y su estatuto de constructo verbal. Por otra parte, problematizaba irónicamente la identificación entre el autor real Julio Cortázar, el narrador del texto y el protagonista del relato: si bien el lector, gracias a la identificación de la situación biográfica del narrador con la del autor, sabía que se trataba del mismo sujeto -o de la ficción del mismo sujeto en diferentes planos-, Cortázar introducía esa fórmula para evitar narrar en primera persona y, de ese modo, mantener una cierta distancia entre esas tres instancias del relato: ${ }^{12}$

\footnotetext{
Barataud (2009) ha desarrollado la idea del collage para comprender la estructura de Fantomas...

${ }^{11}$ La numeración de las citas corresponde a la versión de más sencillo acceso para el lector, la disponible en línea en www.escritores.org

12 Jaime Alazraki (1979: 7) ha señalado cómo en muchas de las ficciones breves de Cortázar la tercera persona funciona como una suerte de encubrimiento de la primera y cómo, en definitiva, la tensión entre tercera y primera persona es estructural en la narrativa de Cortázar.
} 
La reunión de Bruselas del Tribunal Russell II había terminado a mediodía, y el narrador de nuestra fascinante historia tenía que regresar a su casa de París, donde lo esperaba un trabajo bárbaro, razón por la cual no tenía demasiadas ganas de volver; esto explicaba su tendencia a demorarse en los cafés, mirar a las chicas que paseaban por las plazas y revolotear por todas partes como una mosca en vez de encaminarse a la estación (2)

El relato se abría, pues, señalando su carácter eminentemente literario, haciendo visibles las diferentes instancias de la narración -autor, narrador, personaje...- y problematizando las relaciones entre ellas. Del mismo modo en que en algunos filmes de Godard se hacen visibles las cámaras o incluso las operaciones de la sala de montaje, Cortázar trataba de hacer consciente al lector de las convenciones de la narración subrayando sus elecciones formales -como el hecho de convertir al propio Cortázar en narrador y personaje de la narración-. Esa forma de autorreflexividad era, sin embargo, bastante ligera con respecto a las de otros textos cortazarianos y, en cualquier caso, no dificultaba la lectura sino que, por el contrario, la inscribía en el registro lúdico que caracterizaba a Fantomas...

Esa vocación a la vez lúdica y autorreflexiva conducía a una estructura de dos niveles diegéticos que, a medida que avanzaba la acción, terminaban por entrecruzarse. Podría resumirse el proceso de la siguiente manera: el personaje llamado 'el narrador', cuyos datos biográficos y situación existencial le identificaban con el propio Cortázar, leía un cómic de la serie mexicana Fantomas, la amenaza elegante. Se trataba de un cómic real, algunas de cuyas páginas aparecían reproducidas en el relato. Sucedía que, en ese segundo nivel diegético -el de la historia de Fantomas, en la que el héroe se enfrentaba a una organización que pretendía acabar con todos los libros del planeta- Fantomas contactaba a varios escritores, entre ellos Sontag, Paz, Moravia y el propio Cortázar. En un principio, ambos niveles permanecían separados, a pesar de la duplicación: Cortázar el personaje del primer nivel de la historia-identificado con el narrador- leía el cómic en el que aparecía Cortázar como personaje. Pero en un momento de la historia, éstas se cruzaban, a través de una llamada de Susan Sontag, que hacía de nexo entre los dos niveles narrativos:

-Estás enterado, claro -dijo Susan.

-¿De qué? ¿De dónde me hablas? ¿Por qué tengo la impresión de que se trata de algo malo, y eso que no soy telépata ni vidente?

Lo mío no interesa -dijo Susan-, pero después que me rompieron las piernas tuve tiempo para pensar que...

- ¿Las piernas?

-Ah, entonces no estás enterado. ¿Pero cómo puedes no estar enterado si Fantomas te llamó por teléfono antes que a mí?

Lo malo en este tipo de diálogo, solía decirse el narrador, es que se prolongan muchas páginas porque se componen sobre todo de monosílabos, gritos, preguntas espasmódicas, inicios de explicación cortados por nuevas preguntas, y tendencia recíproca a insultarse por la falta de rapidez mental. Todo eso sucedió tal cual, pero podía resumirse de todas maneras en una frase de Susan: “Cuelga y sigue leyendo, estúpido”. Y anota mi teléfono para llamarme después” (12).

A partir de ese momento, los personajes y la historia del segundo nivel entrarían a formar parte del primero, y el propio Fantomas se entrevistaría con Cortázarnarrador, solicitando su ayuda para detener a los conspiradores que habían organizado 
la destrucción de libros a escala planetaria. Esa disolución de los límites entre los diferentes niveles del relato constituía, de hecho, uno de los procedimientos básicos de la poética clásica ${ }^{13}$ de Cortázar, y el principal medio a través del cual algunas de sus historias breves más conocidas producían en sus lectores la sensación de extrañeza que asociamos a ellas: valga señalar el caso de Continuidad de los parques, en el que los personajes de una novela se preparan para asesinar al lector de esa misma novela, o La noche boca arriba, donde los espacios de la vigilia y el sueño se confunden e intercambian a lo largo del relato.

Se trataba, por tanto, de la utilización de un procedimiento típicamente cortazariano pero en un contexto muy diferente al de sus ficciones anteriores. En ese sentido, puede entenderse como una estrategia más para crear un nuevo tipo de narración, en el que la tesis ideológica y la denuncia política no se hallaran reñidas con la exploración de los dispositivos narrativos ni con la producción de efectos de extrañeza en el lector. Es en ese marco creativo en el que se debe entender el gesto de Fantomas. .

\section{UN MUNDO VIOLENTADO: DAR TESTIMONIO MEDIANTE LA FICCIÓN}

Efectivamente, todas esas estrategias de desvío con respecto a la narración tradicional, que Cortázar había ensayado recurrentemente en las décadas anteriores y a las que había siempre otorgado una capacidad de transgresión del orden, se articulaban a otras estrategias de denuncia más directa, que diferenciaban a Fantomas... de los anteriores relatos de Cortázar, con la posible excepción de Libro de Manuel. No por casualidad, esas estrategias narrativas novedosas se hallaban muy emparentadas con las nuevas formas del relato de no-ficción que, en los últimos años, estaban redefiniendo el modo de entender la literatura y su relación con la realidad política en América Latina. Los nuevos géneros testimoniales, que habían modificado el horizonte de expectativas de los lectores y cuestionado las representaciones del intelectual crítico y del escritor comprometido, se habían consolidado a mitad de los setenta como formas de escritura reconocidas por la comunidad de lectores.

En 1975, año de publicación de Fantomas..., Chile se había convertido ya en el espacio de terror y violencia sistemática que caracterizaría a los primeros años de la dictadura militar. Además, se había convertido en un referente del imaginario antifascista y de izquierdas, aglutinando a gran número de intelectuales, asociaciones y movimientos sociales de muchos países en la defensa de la dignidad de los presos chilenos y en contra de la dictadura de Pinochet. En esos primeros años posteriores al golpe, no pocos supervivientes chilenos habían dado testimonio público de sus experiencias en los campos y, en algunos casos, esos testimonios se habían publicado en editoriales literarias, como un nuevo modo de hacer literatura no-ficcional, en sintonía con las nuevas poéticas de denuncia que estaban transformando el concepto de la literatura en América Latina y en otros lugares del mundo. Libros como Tejas Verdes. Diario de un campo de concentración en Chile, de Hernán Valdés (1974), Jamás de rodillas, de Rodrigo Rojas (1974) o Prisión en Chile, de Alejandro Witker

Me refiero, con este adjetivo, a lo que comúnmente se conoce como la poética cortazariana de lo fantástico, que toma como referentes las ficciones de Bestiario, Final del juego, Ceremonias y Todos los fuegos el fuego. 
(1975), habían dado a conocer internacionalmente la naturaleza sistemática de la violencia represiva en Chile, y lo habían hecho a través de la forma testimonial, que comenzaba a ganar espacio cultural a las formas literarias clásicas, cuyo potencial de movilización y de concienciación social parecía entrar en crisis frente a la emergencia de esas nuevas escrituras testimoniales. ${ }^{14}$

La literatura latinoamericana de los años setenta constituyó, en cierta medida, un espacio de tensión entre las poéticas neovanguardistas de los años sesenta y las múltiples formas de literatura denunciante (testimonio, reportaje, factografía...) que comenzaban a ganar la cultura de izquierdas de América Latina. En el último tramo de Libro de Manuel Cortázar ya había abierto la narración a las voces de víctimas de la tortura y a modos del discurso cercanos al reportaje de denuncia política. En Fantomas..., aprovechando el juego narrativo anteriormente comentado, Cortázar traía al relato fragmentos de su biografía reciente, relacionados con el Tribunal Rusell, lo que le permitía aludir a testimonios de supervivientes reales y a algunas de las situaciones que la comisión había analizado. Como puede verse en la siguiente cita, la sola descripción subjetivada del trabajo allí realizado suponía, en sí, un acta de denuncia y una forma de extender al espacio de la narración los presupuestos ideológicos y el gesto acusador que había caracterizado a las actas del Tribunal Russell:

El astuto narrador (...) decidió cerrar la revista y los ojos (...) y resbalar despacito en el tobogán de la fatiga. Ocho días de trabajo en el Tribunal Russell, con una última reunión hasta la madrugada, horas y horas escuchando a relatores y testigos que aportaban pruebas sobre la represión en tantos países de América latina y el papel de las sociedades transnacionales en el pillaje de las economías y la dominación en el plano político y paralelamente, porque la dominación económica exigía otras dominaciones, otros cómplices y otras víctimas, la repetición hasta la náusea de testimonios sobre el asesinato, la tortura, la persecución, las cárceles en Chile, Brasil, Bolivia, Uruguay y no pare de contar. Como un símbolo que ya nadie nombraba, la sombra ensangrentada del Estadio Nacional de Santiago, el narrador creía escuchar otra vez las voces que se sumaban a lo largo del tiempo y los países, la voz de Carmen Castillo narrando ante el Tribunal la muerte de Miguel Enríquez, la voz de los jóvenes indios colombianos denunciando la implacable destrucción de su raza, la voz de Pedro Vuskovic presentando el acta de acusación y pidiendo la condena del gobierno norteamericano (...) Y al salir de todo eso (de la representación mental de todo eso, podía corregir el narrador) se entraba de nuevo en lo personal (...), una mera representación mental de la vida si todo lo otro se borraba con un simple parpadeo y un cambiar de tema. "No se borra”, pensó el narrador, “en todo caso a mí no se me borra” (8-9).

De ese modo, la narración ficcional alojaba modos del discurso que le daban una función muy diferente a la habitual en la poética cortazariana: denunciar una situación histórica de opresión y violencia y legitimar las voces testimoniales de los supervivientes que, desde un registro muy diferente al de la narración literaria, estaban dando cuenta en múltiples foros internacionales de la violencia brutal y sistemática que habían puesto en marcha algunos gobiernos latinoamericanos, especialmente el chileno de Pinochet. De ese modo, la ficción y sus juegos metatextuales abría paso a una dimensión testimonial que nunca llegaba a adquirir verdadera autonomía en el

14 Para un análisis detallado de los testimonios chilenos y de la emergencia del testimonio en el campo literario latinoamericano, ver Peris Blanes (2008). 
texto, pero que parecía determinar, de un modo velado, todo el trayecto narrativo que proponía Cortázar.

Resulta curioso a este respecto cómo, en el largo fragmento anterior, se entrecruza claramente la dimensión documental en la que Cortázar trataba de inscribir su texto con el juego metanarrativo en torno a la figura del narrador: "el astuto narrador", “pensó el narrador”. Si bien el texto se abría conscientemente a un exterior histórico, político y social, lo hacía sometiendo todo el material documental a la lógica narrativa lúdica y exploratoria que ha sido analizada anteriormente.

Si bien la violencia represiva chilena se había convertido en uno de los ejes fundamentales de la denuncia del Tribunal Russell, debido a la meridiana claridad de la naturaleza del régimen militar, en Fantomas... Cortázar se mostraba especialmente interesado en denunciar, asimismo, la situación de violencia política reinante en Argentina. Un año después, con el comienzo de la dictadura militar conocida como El Proceso, la violencia se haría sistemática, estatalmente racionalizada y alcanzaría unas cuotas de intensidad difícilmente predecibles unos años antes, pero lo cierto es que en 1975 la espiral de violencia política ya había comenzado y episodios como el de Trelew y los asesinatos de la Triple A comenzaban a transformar el rostro de Argentina. De nuevo cruzando el juego metanarrativo con la dimensión documental y de denuncia, Cortázar vinculaba la violencia fantástica del cómic con la violencia real que estaba asolando Argentina, y que de algún modo marcaba su historia política.

A Moravia lo habían amenazado con matarlo; al narrador también, pero especificando que lo degollarían. (...) pensó con un vago horror en esa especificación, pensó en el pasado y el presente de su país, en el retorno de un estado de cosas en el que las peores torturas parecían moneda corriente. (...) Cosas así sucedían diariamente en Buenos Aires, en las provincias, con música de radio apagando los alaridos, con noticias de diarios amordazados por el miedo que lo reducían todo a términos como mutilaciones, apremios y vejámenes, la misma Mazorca elogiada en actos públicos, la misma barbarie presentada como reconquista de una patria en la que se hundían hora a hora los cuchillos de la desgracia y el desprecio (15).

\section{CRISIS DEL INTELECTUAL Y DEL RELATO}

Esa emergencia de la dimensión testimonial / documental que convierte a Fantomas... en un espacio de tensión y negociación entre diferentes poéticas, estaba acompañada, en la trama, de un cuestionamiento de la figura del intelectual, de sus valores y actitudes que era, también, una respuesta narrativa a la crisis que la figura del intelectual había sufrido en la segunda mitad de los años sesenta entre la izquierda cultural latinoamericana, y que había culminado en la emergencia de un imaginario antiintelectualista que Claudia Gilman (2003) ha analizado atinadamente.

Cortázar había sido, en los años sesenta, uno de los principales rebatidores de la ideología antiintelectual, ya que siempre defendió la literatura como un espacio de intervención específico de una trascendencia similar a la de la política práctica. En artículos, novelas y entrevistas siempre reivindicó las competencias profesionales del escritor -el trabajo sobre el lenguaje, sobre las estructuras narrativas y sobre la representación del mundo- como su espacio principal de intervención. Proponía 
así, de acuerdo a Gilman, una paridad jerárquica entre la dimensión política, que necesitaba de los hombres de acción para avanzar, y la dimensión cultural, que necesitaba de intelectuales que revolucionaran las representaciones del mundo y el modo en que los sujetos se instalaban en él.

Libro de Manuel, como se ha apuntado, había supuesto una respuesta de primer orden a todo ese debate, y una transformación en la posición de Cortázar al respecto. En la misma línea, Fantomas... trataba de dar una sintaxis narrativa a una nueva concepción del intelectual, y para ello aludía a algunos de los nudos principales de la polémica en torno a las funciones posibles del escritor en la sociedad latinoamericana.

En primer lugar, hacía referencia a ella a través de algunas alusiones irónicas. Por ejemplo, al escribir "aunque el narrador tenía la muy cuestionada costumbre de residir en París” (13) hacía referencia a la recurrente crítica que, en el interior de la polémica, se lanzaba a Cortázar y a otros escritores como Vargas Llosa por vivir en Europa y no en América Latina, lo cual sistemáticamente se identificaba con un alejamiento de la realidad política latinoamericana y con una tendencia a la vida burguesa.

En segundo lugar, y ya de un modo más serio, planteaba una de las cuestiones fundamentales del debate, aunque reformulada de un modo nuevo: la referente a los limitados efectos de la acción intelectual frente a otros modos de la acción política.

Y aun así, qué difícil escapar al calambre de la culpabilidad, de no hacer lo suficiente, ocho días de trabajo para qué, para una condena sobre el papel que ninguna fuerza inmediata pondría en ejecución, el Tribunal Russell no tenía un brazo secular, ni siquiera un puñado de Cascos Azules para interponerse entre el balde de mierda y la cabeza del prisionero, entre Víctor Jara y sus verdugos (8-9)

De hecho, el propio Cortázar había señalado, en las sesiones del Tribunal Russell en México en febrero de 1975, la dificultad de hablar de cuestiones culturales y literarias en el contexto de extrema urgencia política que analizaba la comisión. ${ }^{15}$ En Fantomas... retomaba esa espinosa cuestión, pero ofrecía una salida teórica que legitimaba su obra apuntando a un concepto amplio de revolución, que incluyera la acción armada y la denuncia pública pero también otras formas de acción, propiamente culturales. Si los discursos antiintelectuales que negaban capacidad de transformación a la escritura literaria tenían como referente fundamental a la figura de Che Guevara, ${ }^{16}$ Cortázar utilizaría una de sus frases más conocidas para, comentándola, legitimar su postura: la revolución como exigencia máxima, pero entendida en un sentido amplio y no restrictivo.

El narrador pensó que alguien muy querido había dicho que el primer deber de un revolucionario era hacer la revolución, frase que andaba engolando muchos pescuezos en tierras calientes y templadas, pero a nadie se le ocurría reparar en esa mención casi marginal de "primer deber”, un deber al que seguían otros, puesto que ése era el primero.

\footnotetext{
Llegó a decir: "Hablar de cultura en estos momentos, a pesar de que ella es el elemento natural de mi vida, me avergüenza y casi me humilla, y sin embargo esto no debe ser así, porque es necesario hablar de cultura... El fascismo -concluyó- tiene razón en odiar y temer la cultura popular; ella es la bala de plata que en las antiguas leyendas mata al vampiro, bebedor de sangre, y vuelve más hermosa la salida del sol”, citado por De la Guerra (2000: 175).

16 Efectivamente, tras la muerte del Che en Bolivia hubo un repunte y una radicalización del imaginario antiintelectual en Cuba, que se apoyó en el sacrificio integral de Guevara para criticar el carácter tibio y burgués del trabajo de los intelectuales de izquierdas. Ver Claudia Gilman (2003).
} 
Y esos otros no habían sido enumerados porque no hacía falta, porque al decir esa frase el Che había mostrado una vez más su humanidad maravillosa, había dicho "el primer deber" mientras tanto otros hubieran dicho "el único deber”, y en ese pequeño cambio de nada, una palabrita por otra, estaba el gran matete, la diferencia capital no solamente en las conductas del presente sino en el destino aún tan lejano de cualquier revolución hecha o por hacer (10).

No era la primera vez que Cortázar recurría a la figura de Guevara para dar autoridad a su propia posición en el campo cultural, pero en esta ocasión lo hacía en el interior de un relato, y no en un texto teórico. Si en otros fragmentos la narración se abría a una dimensión documental o testimonial, por momentos viraba hacia el ensayo y hacia la justificación teórica de una determinada concepción de la escritura.

Se trataba, claro, de una idea de la escritura transaccional, que no llegaba a identificarse con ninguna de las posiciones básicas del debate -ni siquiera, y esto es lo importante, con la que Cortázar había desarrollado detalladamente en los años sesenta- pero que trataba de articular en un solo texto concepciones diferentes de la función de la literatura en la sociedad y del potencial político de la escritura. Pero, sobre todo, se trataba de una diferente concepción del intelectual y del rol de la cultura en la sociedad.

De hecho, el cómic original de Matré y Cruz que Cortázar había utilizado como material de base presentaba una trama en la que los libros y la cultura letrada eran tratados como objetos de culto: la banda de malhechores comandada por Steiner conspiraba para destruir todos los libros y todas las bibliotecas del planeta con el objetivo de eliminar los peligros potenciales de la literatura, en una actitud que, en la década de los setenta, no podía dejar de aludir a la actitud de los regímenes dictatoriales del Cono Sur, y especialmente las quemas de libros realizadas por los militares chilenos. ${ }^{17}$ Fantomas, justiciero, esteta y amante de la alta cultura, emprendía una lucha contra esa organización criminal y enrolaba a Sontag, Paz, Moravia y Cortázar en su batalla contra la destrucción de los libros. En ese argumento, la literatura aparecía como el bien más amenazado por una barbarie irracional y paranoica, totalmente desvinculada de la violencia económica, social y física que estaba azotando a los países del Cono Sur en la época.

Cortázar partía de esa trama culturalista, pero le daba irónicamente la vuelta. En primer lugar, la insertaba en otro contexto discursivo, en el que se le obligaba a dialogar con la violencia más real de las dictaduras militares: el del propio Cortázar en el Tribunal Russell, escuchando el relato de supervivientes de torturas y vejaciones y reflexionando sobre la implicación de las empresas multinacionales en la escalada de violencia de Chile, Brasil, Paraguay o Argentina. En segundo lugar, reescribiendo el final de la aventura de Fantomas, denunciando implícitamente su ingenuidad política y ofreciendo otra solución a la historia que reubicara la trama sobre la destrucción de libros en un marco más amplio, que era el que denunciaba la declaración del Tribunal Russell a la que el texto aludía continuamente y que incluía como anexo a la publicación.

\footnotetext{
El propio Cortázar aludiría en otros textos a las quemas de libros como un rasgo definitorio de la represión dictatorial latinoamericana y de su persecución de la actividad cultural: "como es simple imaginar, esa búsqueda de contacto del lector con escritores de su continente multiplica la desconfianza y la cólera de las dictaduras hacia los unos y los otros; cuando la Junta de Pinochet quemó millares de libros en las calles de Santiago, estaba quemando mucho más que papel, mucho más que novelas y poemas, a su siniestra manera quemaba a los lectores de esos libros y a quienes los habían escrito” [1984]: 986.
} 
Lo interesante para la cuestión que nos ocupa es que esa reescritura de la historia del cómic original presentaba una crítica explícita a un cierto tipo de intelectual que, ocupado en defender el arte, se olvidaba de defender a la humanidad o que, dicho en otros términos, se olvidaba de la opresión económica y social para ocuparse sólo de la estética. En ese segundo final -en el primero, el del cómic real, Fantomas había descubierto a los malhechores y parado los pies a Steiner- el personaje ficticio de Octavio Paz hacía referencia a sus propios planteamientos intelectualistas en el cómic de Matré y Cruz, y trataba de corregir su postura: "Somos unos perfectos intelectuales, Julio. Verifica mi diálogo con Fantomas y verás que le pido que haga algo por el amor que profesa al arte. Si pudiera cambiar ese texto, donde dice arte yo hubiera debido decir hombre” (20). Esa crítica del hiperintelectualismo determinaba, de hecho, todo el segmento final, reubicando la trama de la destrucción de los libros en un marco político mucho más amplio.

Ahora él y muchos más sabemos que la destrucción de las bibliotecas no es más que un prólogo. (...) —murmuró Susan (...). Julio, Julio, ¿quién es verdaderamente Steiner? ¿Cómo se llaman los que el Tribunal Russell acaba de condenar en Bruselas? —Se llaman de mil, de diez mil, de cien mil maneras — dijo el narrador con la misma voz cansada, aunque sus piernas estuvieran intactas-, pero se llaman sobre todo ITT, sobre todo Nixon y Ford, sobre todo Henry Kissinger o CIA y DIA, se llaman sobre todo Pinochet o Banzer o López Rega, sobre todo General o Coronel o Tecnócrata o Fleury o Stroessner (21).

Pero la crítica de los personajes reales-ficticios de Cortázar iba más allá: no sólo politizaba la historia anteriormente narrada de acuerdo a las conclusiones del Tribunal Russell, sino que además identificaba la posición culturalista e hiperintelectual de Fantomas como una pantalla frente a los problemas reales del continente. De ese modo, a través del diálogo de sus personajes-intelectuales, Cortázar vehiculaba una crítica a un uso desmovilizador de la cultura y al peligro que suponía la sacralización de la estética en un momento histórico de represión global y de violencia sistémica.

—El Gran Engaño — repitió Susan — la prueba es que hasta Fantomas el infalible se fue de boca con Steiner y su pandilla y creyó que la cosa estaba liquidada cuando no hacía más que empezar. ¿Qué son los libros al lado de quienes los leen, Julio? ¿De qué nos sirven las bibliotecas enteritas si sólo les están dadas a unos pocos? También esto es una trampa para intelectuales. La pérdida de un solo libro nos agita más que el hambre en Etiopía, es lógico y comprensible y monstruoso al mismo tiempo. Y hasta Fantomas, que sólo es intelectual en sus ratos perdidos, cae en la trampa como acabamos de verlo (21).

Esta declaración de principios, que parecía remedar una frase de Sartre pronunciada una década antes, ${ }^{18}$ suponía una inflexión importante con respecto a la idea del intelectual que en los años anteriores había defendido Cortázar en diferentes foros. Puede incluso entenderse como una aceptación de los postulados antiintelectualistas que había combatido fervorosamente en los años sesenta.

18 “QQué significa la literatura en un mundo que tiene hambre? (...) He visto morir de hambre a unos niños. Frente a un niño que se muere, La náusea es algo sin valor” (Sartre, citado por Vargas Llosa 1964: 40). 


\section{LITERATURA Y DENUNCIA PÚBLICA}

El viraje anunciado en la cita anterior tenía repercusiones muy amplias sobre el tramo final del argumento. Si hasta entonces todo había girado en torno a la peripecia fantástica ideada por Mitré y Cruz en la que Fantomas salvaba a la cultura libresca de la desaparición, la parte final del relato trataba de resituar políticamente el problema y de dar el salto que los diálogos anteriores parecían anunciar: del divertimento pulp y metaficcional de las primeras páginas a la denuncia política explícita de las últimas, que se verían además complementadas por la inclusión, como anexo, de las conclusiones formales tomadas por el Tribunal Russell.

Tras el diálogo arriba reseñado, una nueva serie de imágenes vendrían a sustituir a las imágenes del cómic de Mitré y Cruz que anteriormente habían vertebrado la narración. Mucho menos ligadas a la tradición y a la estética del cómic, estas nuevas imágenes inscribían el texto y el argumento fantástico de Fantomas en una dimensión mucho más política. Por ejemplo, un recorte de prensa enviado por Osvaldo Soriano desde Buenos Aires: "Denuncian en Washington un extraño comercio. Venta libre de equipos para asesinar” (22)

En ese nuevo orden narrativo, que sustituía las imágenes del cómic por noticias reales de la prensa y por facsímiles de documentos que probaban, por ejemplo, la implicación de la ITT en el complot contra el gobierno de Salvador Allende en Chile (24-25), también la figura de Fantomas se veía transformada, abriéndose a la posibilidad de una explicación al caso muy diferente a la que había dado en un primer momento:

-Yo también -dijo Fantomas, sentándose en el suelo y sacando un frasco superchato de grapa-, por eso quiero enterarme bien de lo que hicieron ustedes los hipercerebrales en el Tribunal Russell, porque según Susan ahí está el detalle.

-Mirá en los apéndices y encontrarás lo necesario -dijo el narrador mostrando las páginas finales de este mismísimo volumen-. Si querés una síntesis, te la hago en tres palabras: las sociedades multinacionales (23).

El tramo final de la narración, por tanto, se abría a una lógica muy diferente a la que había gobernado la primera parte. En el argumento principal, la abrupta concienciación política de Fantomas derivaba en una trama irónica que situaba a las sociedades multinacionales en el rol de supervillanas. ${ }^{19}$ Pero quizás más importante que ese viraje narrativo eran las conversaciones que los personajes Sontag y Cortázar mantenían en torno a él, y que condensaban una problemática de más largo alcance, que trataba de enlazar las consideraciones sobre la trama de Fantomas con un debate mucho más amplio en torno a las formas de la resistencia y al papel que la literatura y la cultura podían desempeñar en su interior.

En primer lugar, y a partir de la constatación del carácter idealizado, mítico y fantástico del personaje de Fantomas, el personaje de Sontag realizaba un cabal cuestionamiento de los liderazgos políticos revolucionarios, en una apenas velada referencia a la figura de Castro, y abogaba por la necesidad de buscar nuevas formas de lucha:

\footnotetext{
"Como seguir siguió, y poco a poco las agencias de noticias fueron difundiendo los diferentes procedimientos gracias a los cuales Fantomas se había abierto camino en las fortalezas de aluminio y cristal de las sociedades multinacionales" (26).
} 
- ¿Pero tú crees que un día terminaremos por encontrarnos, por reunirnos? Por supuesto estoy de acuerdo contigo, Susan, si llegáramos a eso frente a los vampiros y los pulpos que nos ahogan, si tuviéramos un jefe, un...

-No, Julio, no agregues "Fantomas" o cualquier nombre que se te ocurra. Por supuesto que necesitamos líderes, es natural que surjan y se impongan, pero el error (¿era realmente Susan la que hablaba? Otras voces se mezclaban ahora en el teléfono, frases en idiomas y acentos diferentes, hombres y mujeres hablando de cerca y de lejos), el error está en presuponer al líder, Julio, en no mover ni un dedo si nos falta, en esperar sentados que aparezca y nos reúna y nos dé consignas y nos ponga en marcha (29).

En segundo lugar, se abordaba la cuestión crucial para Cortázar del modo en que la cultura y, más específicamente, la literatura, podría inscribirse en esas nuevas formas de lucha. De entrada, el personaje Cortázar señalaba: “-Susan, nuestros pueblos están alienados, mal informados, torcidamente informados, mutilados de esa realidad que sólo unos pocos conocen” (29) e implícitamente anunciaba una literatura que fuera coherente con esa carencia social y que cumpliera la función esencial de contrarrestar los aparatos de información del capitalismo multinacional. Estaba aquí Cortázar abogando, de nuevo, por ese viraje que había operado en su práctica de escritura desde principios de la década de los setenta, y que había desplazado la experimentación neovanguardista que había caracterizado a sus textos de los sesenta hacia el registro de la denuncia política explícita.

Las últimas páginas del texto trataban de cerrar de forma coherente las diferentes líneas de sentido que, a lo largo del relato, se habían ido abriendo. Cortázar recurría para ello a una escena de una amplia irradiación metafórica: la articulación de un conjunto de voces heterogéneas en el teléfono, una de las cuales exponía las conclusiones más llamativas a las que había llegado el Tribunal Russell y entraba en diálogo con otras que expresaban la posición de ciudadanos anónimos de diferentes lugares del mundo. Esa escena permitía, al menos, dos operaciones simultáneas: por una parte, abrir el texto narrativo, y ya de forma explícita, a las conclusiones del Tribunal; ${ }^{20}$ por otra, proponer la imagen simbólica de las voces en diálogo como metáfora de una nueva matriz de relaciones humanas. ${ }^{21}$ Frente al panorama desolador que describía el informe y que había sobrevolado a toda la narración, el texto se cerraba con una cierta invitación a la esperanza, que daba sentido a su propio subtítulo: Una utopía realizable.

-Lo bueno de las utopías - dijo claramente una voz afrocubana que resonaba como un cascabel-, es que son realizables. Hay que entrar a fajarse, compañero, del otro lado está el amanecer, y yo te planteo que...

20 "El locutor parecía estar esperando, y los demás también, porque hubo un gran silencio y entonces: -El Tribunal declara que en el caso de la junta militar presidida por el general Pinochet en Chile, ésta se encuentra en una situación de completa violación del derecho internacional y no merece ser considerada miembro integrante de la comunidad integrada de las naciones; Condena a los gobiernos de los Estados que alientan tales procederes; Condena por este hecho a los Presidentes Nixon y Ford, a los gobernantes de los Estados Unidos de América y especialmente al señor Henry Kissinger, cuya responsabilidad en el golpe fascista de Chile es evidente para el Tribunal, juzgando sobre los documentos publicados en los Estados Unidos” (30).

21 "Del hueco sonoro venían voces, acentos, gritos, llamadas, afirmaciones, noticias; se sentía como si muchedumbres lejanísimas se juntaran en el oído del narrador para fundirse en una sola, incontenible multitud. Frases sueltas saltaban con acentos brasileños, guatemaltecos, paraguayos, y los chilenos pulidos y los argentinos a grito pelado, un arco iris de voces, una inatajable catarata de pechos y de voluntades” (32). 


\section{CONCLUSIONES}

Fantomas contra los vampiros multinacionales supuso, pues, un esfuerzo por conciliar diferentes poéticas que habían entrado en conflicto hacía, por lo menos, una década en América Latina, y por hallar una sintaxis narrativa eficaz que, sin renunciar a los postulados cortazarianos sobre la narración -el lector cómplice, el juego metanarrativo entre diferentes niveles diegéticos, el diálogo entre diferentes soportes, el carácter abierto de las tramas, la paradoja autoficcional, etc.- abriera el texto a una dimensión social muy diferente, la de denuncia explícita de las formas de dominación, explotación y represión contemporáneas. En ese sentido, Fantomas... se proponía a la vez como un paratexto de las conclusiones del Tribunal Russell, que sin duda contribuyó a difundir, y como una reflexión sobre las posibilidades de la cultura en el panorama de las nuevas luchas políticas en América Latina.

Fantomas... era, pues, un espacio de negociación entre diferentes formas de entender la literatura en relación a los procesos sociales y políticos que se estaban viviendo en América Latina en la década de los setenta. En ese sentido, retomaba los términos de la discusión y los cuestionamientos que ya había ensayado en Libro de Manuel, pero con sensibles variaciones. En primer lugar, se trataba de un relato que situaba en el centro a códigos propios de la cultura masiva, con la intención explícita de ampliar el campo potencial de recepción y, de ese modo, las posibilidades de impacto de su texto. En segundo lugar, la dimensión documental y testimonial que ya había aparecido en Libro de Manuel se ligaba aquí, de un modo muy concreto, a la necesidad de hacer públicas las conclusiones del Tribunal Russell, que aparecían mencionadas y comentadas en todo el relato y que se incluían como apéndice en su edición original. En tercer lugar, si Libro de Manuel se cerraba con la muerte del narrador y su sustitución por la enunciación testimonial, en un espacio tan violentado que parecía negar la posibilidad misma de la literatura de ficción, Fantomas... integraba ya en su subtítulo la posibilidad de una esperanza político-literaria, una utopía realizable que quedaba indefinida y sin desarrollar en el texto, pero que daba una tonalidad diferente al relato y a la apuesta estético-política que le acompañaba.

\section{OBRAS CITADAS}

Alazraki, Jaime. 1979. "Voz narrativa en la ficción breve de Julio Cortázar". Inti: revista de literatura hispánica 10: artículo 19.

Alburquerque Fuschini, Germán. 2001. "El caso Padilla y las redes de escritores latinoamericanos”. Universum 16: 307-320.

Barataud, Marie-Alexandra. 2009. "Del texto y de la imagen: la escritura transgenérica en Fantomas contra los vampiros multinacionales de Julio Cortázar” Journées d'etudes et colloques du SAL III. En línea; disponible en http://www.crimic.paris-sorbonne.fr/sal/ spip.php?article215

Casal, Lourdes. 1971. El caso Padilla. Literatura y revolución en Cuba. Documentos. Miami: Ediciones Universal.

Cortázar, Julio. 1975. Fantomas contra los vampiros multinacionales. Una utopía realizable. México DF: Excelsior. Edición digital en http://www.literatura.org/Cortazar/Fantomas/index.html

[1969] 2006. "Literatura en la revolución y revolución en la literatura: algunos 
malentendidos a liquidar” Obras completas VI. Barcelona: Galaxia Gutenberg. 399-422. . [1984] 2006. "El lector y el escritor bajo las dictaduras en América Latina” Obras completas VI. Barcelona: Galaxia Gutenberg. 980-989.

De la Guerra, Francisco Emilio. 2000. Julio Cortázar, de literatura y revolución en América Latina. México: Unión de Universidades de América Latina.

De la Nuez, I. 2006. Fantasía roja. Los intelectuales de izquierdas y la Revolución cubana. Barcelona: Debate.

Eco, Umberto. 1965. Obra abierta. Forma e indeterminación en el arte contemporáneo. Barcelona: Seix Barral.

Franco, Jean. 2003. Decadencia y caída de la ciudad letrada. La literatura latinoamericana durante la Guerra Fría. Barcelona: Debate. . 1979. “Cortázar: Utopía and Everyday Life” Inti: revista de literatura hispánica 10: artículo 15.

Gilman, Claudia. 2003. Entre la pluma y el fusil. Dilemas y debates del escritor revolucionario en América Latina. Buenos Aires: Siglo XXI.

Guevara, Ernesto. [1965] “El socialismo y el hombre en Cuba” en Desnoes, E. 1981. Los dispositivos en la flor. Cuba: literatura desde la revolución. Hanover: Ediciones del Norte. 525-532.

Gundermann, Charles. 2001. "La revolución más profunda: Julio Cortázar entre literatura y política revolucionaria”. Horizontes 84: 30-50.

Herráez, Miguel. 2001. Julio Cortázar. El otro lado de las cosas. Valencia: Ronsel.

Pérez-Stable, Marifeli. 1993. The cuban revolution. Nueva York: Oxford University Press.

Peris Blanes, Jaume. 2006. “Libro de Manuel, de Julio Cortázar, entre la revolución política y la vanguardia estética” Cuadernos de Investigación Filológica 31-32: 143-161. . 2008. Historia del testimonio chileno. De las estrategias de denuncia a las políticas de memoria. València: Quaderns de Filología.

. 2009. "La policrítica de Cortázar. La autonomía de la literatura ante las exigencias de la revolución” Hesperia: Anuario de Filología Hispánica 12, 2: 89-105.

Standish, Peter. 1997. “Los compromisos de Julio Cortázar” Hispania 80/3: 465-471.

Vargas Llosa, Mario [1964] 1983. "Los otros contra Sartre” Contra viento y marea (19621982). Barcelona: Seix Barral. 38-42. 